\title{
The effects of using mobile and smart devices at work
}

\author{
Beata Bittner, University of Debrecen, bittner.beata@econ.unideb.hu \\ Adrian Szilard Nagy, University of Debrecen,nagy.adrian@econ.unideb.hu \\ Maria Ujhelyi, University of Debrecen, ujhelyi.maria@econ.unideb.hu
}

\begin{abstract}
As a result of the epidemic sweeping the world, technologies and tools have been integrated into everyone's lives and work, which employers use and exploit in the course of their work. Numerous studies have been conducted on the labor market effects, positive and negative consequences of mobile devices. The impact of smartphones on work-life balance is now unquestionable, as employees use their phones in the workplace to deal with their private affairs as well as their work tasks in their free time, they cannot exclude their work tasks by tracking their e-mails and reading messages, by detecting or even receiving incoming corporate calls and messages. International studies (Miller-Merrell, 2012; Anderson, 2010) mention the positive effects of using smart devices in the workplace, the faster flow of information, or even the lower time and cost of exchanging information. Face-to-face meetings can be triggered by video conferencing, e-mail, messages. The place to work has become flexible in many cases; we can participate in a video conference from home or a café in the same way as sitting in the workplace. Another positive effect is employee satisfaction with allowing their mobile phones (Noell, 2014). Increases in working time to the detriment of privacy, ongoing stress, and declining productivity are often cited as negative effects (Bozeman, 2011; Ebelhar, 2009; Rush, 2011; Smith, 2012; Economist 2019; Morris 2015). In this paper, the authors examine the opinion and experiences of employees on this topic in Hungary.
\end{abstract}

Keywords: mobile devices, smartphones, business communication

\section{Introduction}

Due to the rapid development of technology, mobile and smart devices have become natural nowadays. Generations Y and Z, which are already present in the labor market, have grown up using them, so for them, they are natural supplements of everyday life, which they do not like to miss while working. Of course, technologies and tools have been integrated into previous generations' lives and work, which employers also use and exploit in the course of their work.

The impact of smartphones on work-life balance is now unquestionable, as employees use their phones in the workplace to deal with their private affairs as well as their work tasks in their free time, they cannot exclude their work tasks by tracking their e-mails and reading messages. by detecting or even receiving incoming corporate calls.

Numerous studies have been conducted on the labor market effects, positive and negative consequences of mobile devices. The impact of smartphones on work-life balance is now unquestionable, as employees use their phones in the workplace to deal with their private affairs as well as their work tasks, but in their free time, they cannot exclude their work tasks by tracking their e-mails and reading messages, by detecting or even receiving incoming corporate calls and messages. 


\section{Issues in Information Systems}

Volume 22, Issue 1, pp. 227-235, 2021

\section{Background and literature review}

According to data from GSMA Intelligence - the world's most prominent mobile phone service industry researcher - in 2019, the world's 7.71 billion people generated 8.97 billion mobile connections, an average of 1.16 connections per capita, growing dynamically to nearly 11 billion by April 2021 . According to the survey, $66.5 \%$ of the world's population has a mobile phone, $35.1 \%$ is a smartphone. In terms of mobile and smartphone use and mobile internet connections, Europe leads with $85 \%$ of its total population, ahead of North America. (gsmaintelligence, 2021).

There is no sharp separation between work and private life during mobile telephony in the workplace. According to a Hungarian survey by Nagy and Radó (2014), only 15\% of employees say that they use their mobile phones only for work during working hours and only for private purposes in their free time. Their results show that people use mobile phones for private purposes in the workplace rather than outside of working hours (Figure 1.). While $80 \%$ of respondents use their mobile phone for private purposes with different frequencies but during working hours, only $59 \%$ of respondents said that they use their mobile device more or less often for work-related matters during holidays or public holidays, and $70 \%$ say that he said he does work on weekdays, not during working hours. However, a significant difference was observed between blue- and white-collar workers (i.e., workers and office workers). In the workplace, white-collar workers use their cell phones to a much greater extent than blue-collar workers to handle work-related matters.

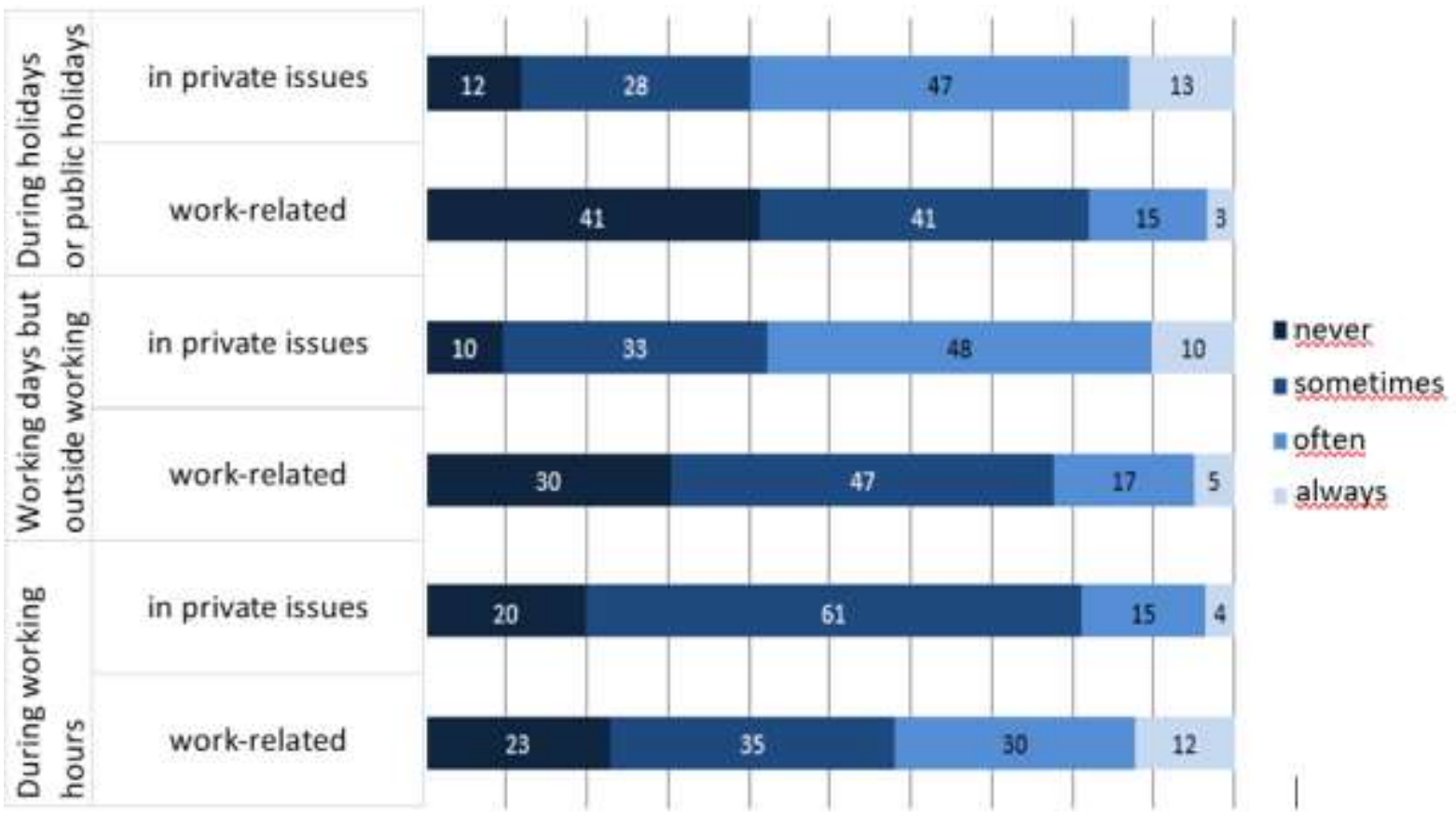

Figure 1. Use a mobile phone to make phone calls and email

Source: Nagy - Radó, 2014

eNET was also surveyed on the same topic in 2017 in Hungary. According to eNET's online research, $86 \%$ of active, working Hungarians use a smartphone. $64 \%$ of them insist that they can use their phones for personal activities during working hours. In the survey, seven out of ten respondents used to make regular (at least once a week) private phone calls during their working hours, and more than half of them write or read SMS, chat, or e-mail (also). In addition to communication, non-work-related browsing $(54 \%)$, visiting social media sites $(52 \%)$, and reading online news sites on smartphones are also very popular (51\%), for which respondents also take time off during working hours (eNET, 2019). 


\section{Issues in Information Systems}

Volume 22, Issue 1, pp. 227-235, 2021

\section{Positive and negative effects of using a mobile phone at work}

Many companies use internal communication platforms (e.g., internal social networks, internal chat programs), that are fundamentally similar to public platforms, except that they provide a private and secure channel to reach employees.

This type of communication can result in significant time savings. Its appearance provides much broader opportunities for individuals; people have become available at all times, what the jargon calls "constant touch", or "perpetual contact" or "connected relationship" (Wajcman, - Bittman - Brown, 2008).

Another important argument in favor of encouraging the use of telephones is to strengthen the relations among employees. Many people contact their co-workers or managers more directly and quickly by phone or chat than in person. Another advantage is the possibility to share information and knowledge. Phones and applications offer a virtual collaboration platform that prevents e-mail mailboxes from being overloaded (Miller-Merrell, 2012).

One of the most influential and popular knowledge-sharing tools is "cloud-based" computing, such as GoogleDocs (Anderson, 2010). Using these applications in the workplace allows employees to be informed immediately, and shared cloud-based services enable simultaneous work anywhere, anytime. It makes it easy to bridge geographical differences, the time lag to a certain level. The fast flow of information facilitates efficient task solutions. These benefits contribute to employee satisfaction, which can increase their efficiency. Cellphone using counts in positive use for organizations as it is essential to know the market and share information and keep in touch with clients and superiors (Wahla-Awan, 2014, Pitichat, 2013). Cellphone use has a positive impact on work experience and the ability to solve problems on the spot effectively. Finally, smartphone promotes autonomy in a workplace, making employees feel good.

Increases in working time to the detriment of privacy, ongoing stress, and declining productivity are often cited as negative effects (Bozeman, 2011; Ebelhar, 2009; Rush, 2011; Smith, 2012; Economist 2019; Morris 2015). Smartphone usage negatively affects attention as the focus is on chatting, listening to music, and other activities, while academic activities are neglected and left to suffer. When employees use their smartphones to work on their projects from their work, sometimes they bring stress from their workplaces into their private lives at home, so they cannot separate their work and non-work lives.

In this paper, the authors examine the opinion and experiences of employees on this topic in Hungary.

\section{Methodology}

In this paper, the authors examined the effects of using mobile and smart devices on work. Both primary and secondary research was conducted to prepare the study. Within the framework of secondary data collection, the literature and databases related to the topic were processed.

It was followed by primary research, using a questionnaire survey. After testing, correcting, and completing the questionnaire, 341 questionnaire responses were analyzed after data cleansing. The questionnaire was evaluated using Microsoft Excel and SPSS 25.0.

We used the descriptive statistical method; here, the averages, standard deviations, and frequencies were highlighted and plotted in diagrams and tables. Correlation studies were then performed. One of the most commonly used methods for analyzing relationships between variables is correlation and regression calculations. In further steps, where the sample numbers of the subgroups allowed, crosstabulations were used. If there was also an ordinal variable in the database, a Kruskal-Wallis test was performed. 


\section{Issues in Information Systems}

Volume 22, Issue 1, pp. 227-235, 2021

It is important to note that the research was conducted just a year ago before the Covid19 epidemic spread in Europe. As we know, due to the pandemic, many organizations have switched to teleworking, so the use of communication tools for work has increased significantly. Therefore, the results of the present research can be applied to a regular working order operation.

\section{Results}

Respondents - from the valid 341 questionnaires - were 242 women and 99 men by gender. In Figure 2., the age distribution shows that one-third of the respondents were in the $30-40$ age group $(115,33 \%)$. Another quarter of the respondents (86 people, 25\%) were 41-50 years old, 15-15\%, ie. 50-52 people, were 26-30, and 51-60 years old. 34 respondents (10\%) were under 25 and 4 were over 61 years.

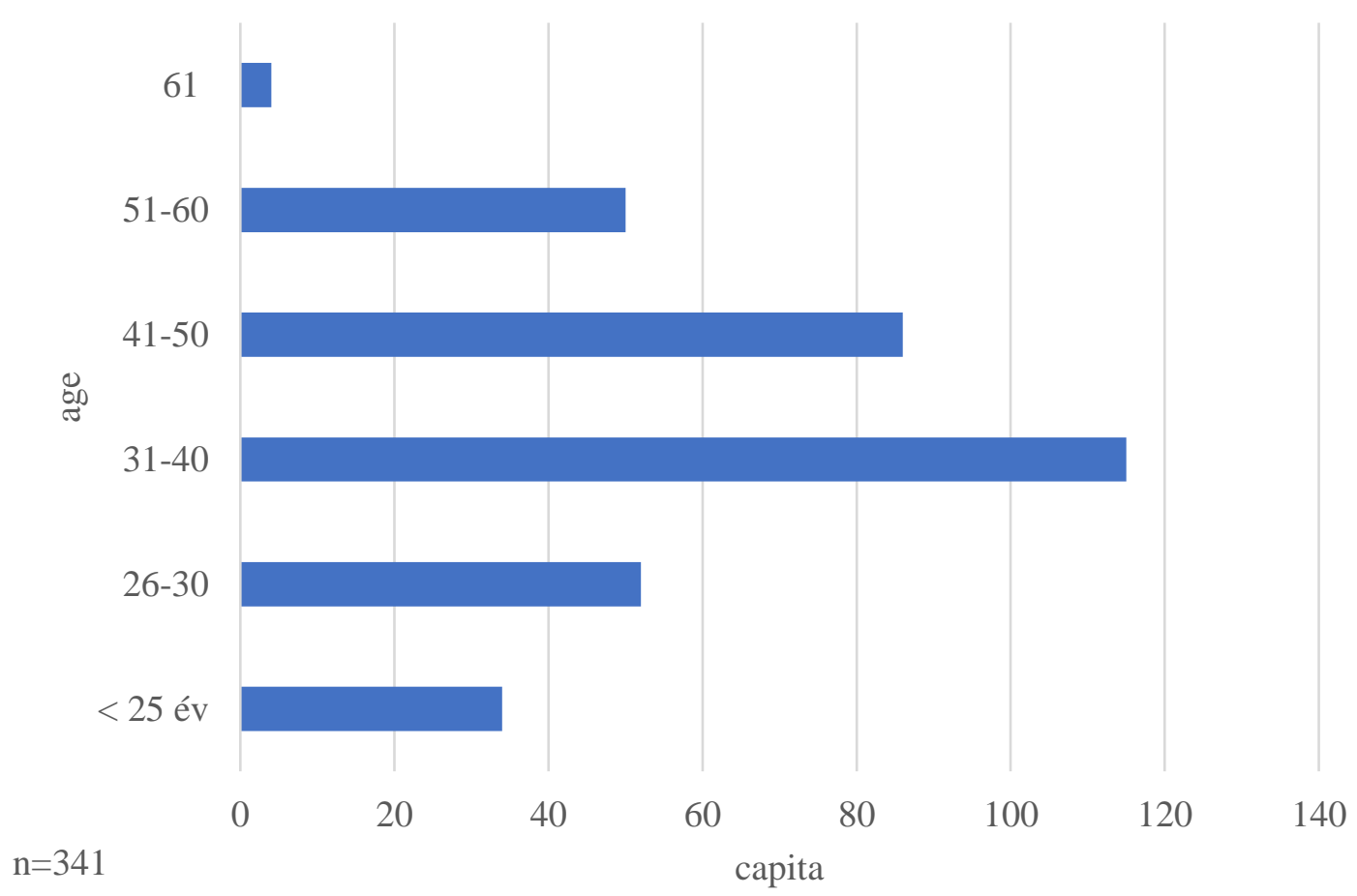

Figure 2. Distribution of respondents by age Source: own data, 2020

Two-thirds of the respondents have a tertiary education and one-third have a secondary education. On the one hand, the majority of tertiary education is in line with the national trend, which means a high proportion of tertiary education. On the other hand, it occurred because there are typically more individuals with tertiary education on the chosen sharing surfaces.

In terms of the workplace, $32 \%$ of respondents fill the public sector and $68 \%$ work in the private sector. This question of mine provides an opportunity to examine the differences between the public and private sectors later.

In the work schedule, the majority were employees working 8 hours a day; about two-thirds $(65 \%)$ of the respondents belong to this category. $10 \%$ work part-time, $20 \%$ work $8-12$ hours, and 5\% work more than 12 hours/day.

More than half of the respondents (55\%) work in a fixed, one-shift work schedule, $34 \%$ in a casual working schedule, and $11 \%$ in a two-shift or multi-shift schedule. $64 \%$ of respondents, i.e., 218 people, 


\section{Issues in Information Systems}

Volume 22, Issue 1, pp. 227-235, 2021

need to use a telephone to work now, and 34\%, i.e., 123 people, do not need a telephone for their work according to their answers.

The questionnaire's next question was about "how much time you spend using the phone, including messaging, exchanging messages on chat programs, visiting websites, and making phone calls." The responses are illustrated in Figure 8. In the highest proportion, 42\%, respondents indicated 3-4 hours per day. An additional 34\% use their phones 1-2 hours a day, 12\% use 5-6 hours a day, 4\% more than 6 hours a day, and $8 \%$ use less than 1 hour a day.

The next question was about what proportion of telephone use is closely related to work. More than half of the respondents indicated $0-25 \%$, about a quarter $25-50 \%$, and the remaining $21 \%$ indicated an even higher proportion. The response of the self-employment category, in this case, was $100 \%$.

Besides calls, the most commonly used platforms for work are e-mail and messaging through various chat programs (Hangouts, Messenger, Viber, Whatsup). A significant proportion also marked text messaging and cloud-based services, and communication on self-developed internal systems also accounted for a significant proportion. It should be noted that teleworking and distance learning due to Covid necessitated and popularized the use of many platforms that were not yet widespread among the respondents at the questionnaire (Teams, Zoom, Webex, etc.).

For the question "when the telephone platforms are used for official (work-related) communication?", $12 \%$ of respondents indicated that they do not use it, $21 \%$ only during working hours. Of the 341 respondents, 223 (67\%) indicated that they look for each other with their colleagues outside office hours on a formal matter. When we were looking for the answer to what dates this contact falls, a significant proportion (80 people, $25 \%$ ) answered that all day (and night) on weekdays, as well as on weekends and public holidays (117 people, $37 \%$ ). This response confirms the extension to the detriment of privacy due to such communication opportunities. However, this proportion stays behind the results of the 2014 domestic research presented in the literature section. 59\% of respondents said they use their mobile devices more or less often for work-related matters during holidays or public holidays. $70 \%$ said they do work on weekdays, not during working hours.

The following question was about the reaction of employees to formal inquiries outside working hours. Only $5 \%$ of respondents ignore them. $6 \%$ occasionally checks their incoming messages and e-mails but does not respond to them. Nearly half of respondents (47\%) also respond to messages after occasionally checking their phone, and a further $42 \%$ check as soon as they detect an incoming message, of which $35 \%$ of all respondents respond immediately.

The last part of the questionnaire surveyed attitudes related to telephone use. The results are shown in Table 1. The questionnaire contained various statements regarding telephone use. Respondents were asked to mark on a 5-point scale the value that most expresses their opinion. 5 means fully agrees with the statement/fully characterizes the statement, while a 1 means strongly disagrees/does not characterize the answer at all. 


\section{Issues in Information Systems}

Volume 22, Issue 1, pp. 227-235, 2021

Table 1. Statements regarding telephone usage

\begin{tabular}{|l|c|c|c|c|c|c|}
\hline \multicolumn{1}{|c|}{ States } & $\mathbf{5}$ & $\mathbf{4}$ & $\mathbf{3}$ & $\mathbf{2}$ & $\mathbf{1}$ & Sum \\
\hline $\begin{array}{l}\text { Taking advantage of the opportunities provided by } \\
\text { mobile / smartphone (chat, e-mail..) significantly } \\
\text { contributes to my efficient work }\end{array}$ & $\mathbf{3 8 , 5}$ & 26,0 & 17,5 & 8,3 & 9,8 & $\mathbf{1 0 0 , 0}$ \\
\hline $\begin{array}{l}\text { It gives me satisfaction to be able to handle personal } \\
\text { issues over the phone at my workplace }\end{array}$ & $\mathbf{5 0 , 6}$ & 27,4 & 13,2 & 5,6 & 3,2 & $\mathbf{1 0 0 , 0}$ \\
\hline $\begin{array}{l}\text { I expect my colleagues to be available by phone or } \\
\text { message (e-mail, chat, sms) outside working hours }\end{array}$ & 18,3 & 15,1 & 20,4 & 18,9 & $\mathbf{2 7 , 2}$ & $\mathbf{1 0 0 , 0}$ \\
\hline $\begin{array}{l}\text { My co-workers expect me to be available by phone or } \\
\text { message outside of working hours }\end{array}$ & 19,2 & 21,5 & $\mathbf{2 5 , 7}$ & 16,5 & 17,1 & $\mathbf{1 0 0 , 0}$ \\
\hline $\begin{array}{l}\text { If I couldn't use a phone at work, I would think about } \\
\text { changing jobs }\end{array}$ & 18,8 & 11,6 & $\mathbf{2 8 , 1}$ & 14,6 & 26,9 & $\mathbf{1 0 0 , 0}$ \\
\hline $\begin{array}{l}\text { I can "leave" my job and the stress that comes with it } \\
\text { at work }\end{array}$ & 18,3 & $\mathbf{2 6 , 3}$ & $\mathbf{2 6 , 6}$ & 13,9 & 14,8 & $\mathbf{1 0 0 , 0}$ \\
\hline $\begin{array}{l}\text { Messages received from mobile / smartphone (chat, e- } \\
\text { mail/) impair my work }\end{array}$ & 4,2 & 5,7 & 21,1 & 26,8 & $\mathbf{4 2 , 3}$ & $\mathbf{1 0 0 , 0}$ \\
\hline $\begin{array}{l}\text { I easily wander off while working and forget about } \\
\text { my phone }\end{array}$ & 2,4 & 9,5 & 15,4 & 24,6 & $\mathbf{4 8 , 1}$ & $\mathbf{1 0 0 , 0}$ \\
\hline \begin{tabular}{l} 
It bothers me to look outside of working hours \\
\hline
\end{tabular} & 17,6 & 21,5 & $\mathbf{2 9 , 0}$ & 16,4 & 15,5 & $\mathbf{1 0 0 , 0}$ \\
\hline
\end{tabular}

Source: own data collection and editing, 2020

In addition to the questionnaire's descriptive statistical evaluation, correlation studies were performed to identify the differences according to each background variable.

First, we performed a correlation calculation to establish the relationships between the data, where we found a relationship between the variables, we further examined the relationship. The variables examined were:

- age and time spent using the phone

- telephone use related to work outside of age and working hours

- age and response to handling messages received after business hours

- age and platforms used

- relationships between age and attitudes related to mobile device use

- examining the differences between the public and private sectors in the use of the telephone in connection with work outside working hours

- differences between the public and private sectors in terms of mobile device usage attitudes

- gender and time spent using the phone

- telephone use related to gender and after-hours work

- gender and reaction to handling messages received after business hours

- not and used platforms

- relationships between gender and attitudes related to mobile device use

- education and time spent using the telephone 


\section{Issues in Information Systems}

Volume 22, Issue 1, pp. 227-235, 2021

- education and platforms used

- correlations between education and out-of-hours telephone use

Only those categories are detailed below where there was a significant relationship between the factors. There was a weak correlation between age and time spent using the telephone, with young workers under the age of 30 spending significantly more time using their telephones than employed over the age 60 , based on the responses.

Different behaviors could be detected in the habits of two age groups compared to the others. The first is the 51-60 age group, who, to some surprise, use the e-mail interface significantly less than the other age groups. They use significantly less the various chat programs and cloud-based services, too. In the age group under 25, map interfaces showed a lower use rate compared to the other groups.

Examining the statements I made about attitudes related to telephone use by age group, there was no significant difference between opinions in most cases. The only exception was the statement that "If I couldn't use a phone at work, I would think about changing jobs" the age group over 51 marked 1, significantly more times than other groups.

There was a difference between the platforms used by women and men: men use all platforms at a higher rate than female respondents. There was a significant positive difference across multiple platforms, including in the categories of e-mail, text messaging, chat programs, cloud-based services, and map services in favor of men.

Analyzing the relationship between responders' education level and telephone use, we found a significant correlation at several points. Low-educated people use their phones significantly less than higher-educated people.

There was also a significant difference between the platforms used in terms of education, as well. Each of the categories with a mid-level education showed a significantly lower low value for respondents with higher education in the case of e-mail, cloud-based services, and internally developed systems.

Finally, most lower educational people do not use a telephone to work with their co-workers outside of working hours, according to the answers. Only $0-25 \%$ of the telephone use among the elementary graduates and those with vocational and secondary education can be related to work. For those with higher education, this proportion was much higher.

\section{Conclusions}

Most employees also receive a work-related call or message on holidays or public holidays, and they check their phones on these days as well, so it can be said that this type of communication is at the expense of rest.

The daily use of mobile and smart devices among the respondents coincided with the international trends, i.e., an average user spends 3-4 hours using them at home.

The studies described in the literature section have discussed the negative effects at length. We also examined several of these factors in the questionnaire. It includes distractions caused by the use of telephones and thus a reduction efficiency. However, this was not substantiated by the replies to the questionnaire.

The negative effects also included an increase in stress due to continuous contact. Whether or not this is due cannot be judged from the particular questionnaire, but it is a fact that the majority of respondents, especially men, take work-related stress home. 


\section{Issues in Information Systems}

Volume 22, Issue 1, pp. 227-235, 2021

Other negative effects in the studies were the upsetting of work-life balance, the extension of working hours due to mobile and smart devices, and constant contact. The answers to the questionnaire revealed that formal inquiries outside working hours are present in most of the majority in almost all periods, to which the vast majority respond, so it can be stated that this is in line with the results of international studies.

Positive effects in international studies include increased work efficiency and employee satisfaction. The replies also supported these two aspects to the questionnaire. Based on these, it is recommended to use these platforms during working hours and consider possible restrictions on the use of telephones during working hours.

Overall, based on the responses to the questionnaire, it can be stated that the majority of employees have a more favorable opinion on work-related telephone use; the negative effects were less pronounced in contrast to the results of international research. This assumes that workers are more tolerant in this area than they assume.

Finally, due to Covid, a significant number of businesses have introduced the home office option, so in 2020 these values and perceptions of mobile and smart device usage may have changed significantly. For this reason, we consider it necessary to repeat the research and compare the new results with our current results. It can be assumed that by lifting the restrictions due to covid, home office working will be decreased again; however, it can already be predicted that the role of digital communication will not decrease to the initial level.

\section{References}

Anderson, J.Q. - Rainie, L. (2010). The future of cloud computing. Pew Research Center's Internet\& American Life Project. http://pewinternet.org/Reports/2010/The-future-of-cloudcomputing.aspx

Bozeman, M. (2011, July 27). Smartphone obsession the latest addiction. Bozeman Daily Chronicle.

Ebelhar, J. (2009). Mind your BlackBerry or mind your manners. The New York Times Jun 21, 2009.

ECONOMIST (2012): Slaves to the smartphone, The horrors of hyperconnectivity - and how to restore a degree of freedom in: The Economist

https://www.economist.com/business/2012/03/10/slaves-to-the-smartphone

eNET (2017): Okostelefonnal jobban összemosódik a munka és a magánélet, eNET Internetkutató és Tanácsadó Kft., https://enet.hu/hirek/okostelefonnal-jobban-osszemosodik-a-munka-es-amaganelet/

GSMA Intelligence (2021): The Mobil Economy 2019, GSMA Intelligence, WorldoMeters U.N. data, GSMA Intelligence, https://www.gsmaintelligence.com/data/

Miller-Merrell, J. (2012). The workplace engagement economy where HR, social, mobile, and tech collide. Employment Relations Today. p.1-9.

Morris W. (2015), Technology addiction IAAP Edge, November 24, 2015

Nagy B. - Radó M. (2014): A mobiltelefonok használata és a munka és a magánélet közötti határok elmosódása, http://old.tarki.hu/hu/news/2015/kitekint/20150107_mobil.html 


\section{Issues in Information Systems}

Volume 22, Issue 1, pp. 227-235, 2021

Noell, M. (2014). Study: smartphone "microbreaks" during work day are productive. from http://www.kltv.com/story/26044621/study-smartphone-microbreaks-during-work-day-areproductive

Pitichat, T. (2013) Smartphones in the workplace: Changing organizational behavior, transforming the future. LUX J. Transdiscipl. Writ. Res. Claremont Grad. Univ. 2013, 3

Rush, S. (2011). Problematic use of smartphones in the workplace: an introductory study, BArts (Honours) thesis, Central Queensland University, Rockhamtom. http://hdl.cqu.edu.au/10018/914191

Smith, A. (2012). $46 \%$ of American adults are smartphone owners phones within, Pew Research Center's Internet \& American Life Project. Retri http://pewinternet.org/Reports/2012/Smartphone-Update-2012.aspx

Wahla, R.S.; Awan, A.G. (2014) Mobile phones usage and employees' performance: A perspective from Pakistan. International Journal of Academy Research in Accounting, Finance and Management Science, 4, 153-165.

Wajcman, J. - Bittman, M. - Brown J. E. (2008): Families without Borders: Mobile Phones, Connectedness and Work-Home Divisions, SAGE Publications DOI:

10.1177/0038038508091620 ttp://journals.sagepub.com/doi/abs/10.1177/0038038508091620 